\title{
DESENVOLVIMENTO E AVALIAÇÃO SENSORIAL DE IOGURTE COM SEMENTES DE CHIA
}

\section{Development and sensory evaluation of yogurt with chia seeds}

\author{
Melina Vilela dos Santos ${ }^{1}$, Richtier Gonçalves da Cruz ${ }^{2}$, Martha Elisa Ferreira de Almeida ${ }^{1 *}$
}

\section{RESUMO}

O objetivo deste estudo foi desenvolver e avaliar a aceitação sensorial de formulações de iogurte com sementes de chia. Após a elaboração das formulações (A - controle, B - iogurte adicionado de $2 \%$ de sementes de chia, C - iogurte adicionado de $3 \%$ de sementes de chia) realizou-se análises microbiológicas e físicoquímicas. Utilizou-se escalas hedônicas para verificar a aceitação e a intenção de compra das formulações elaboradas, bem como o Índice de Aceitabilidade. Os dados dos testes de aceitação e intenção de compra foram avaliados por meio de Análise de Variância (ANOVA) e, posteriormente, aplicou-se Teste de Tukey a 5\% de probabilidade. As formulações de iogurte estavam dentro dos padrões exigidos pela Legislação Brasileira quanto às análises microbiológicas e físico-químicas. Não houve diferença significativa $(\mathrm{p}>0,05)$ entre as 3 formulações de iogurte para os atributos sabor, textura e impressão global. Entretanto, quanto ao atributo aparência, a formulação com $3 \%$ de sementes de chia (C) foi menos apreciada $(\mathrm{p}<0,05)$ que a formulação controle (A). As formulações com sementes de chia (B e C) tiveram uma boa aceitação sensorial pelos avaliadores e o atributo sabor foi o de maior destaque. Dentre as formulações com sementes de chia, a formulação B apresentou o melhor Índice de Aceitabilidade. Não houve diferença significativa $(\mathrm{p}>0,05)$ quanto à média das notas na intenção de compra para as 3 formulações de iogurte. Conclui-se que as formulações de iogurtes com sementes de chia apresentaram-se adequadas quanto aos parâmetros microbiológicos e físico-químicos ao longo do período de armazenamento, além de obter uma boa aceitação sensorial, apresentando-se como uma alternativa láctea mais saudável para os consumidores.

1 Universidade Federal de Viçosa, Campus Rio Paranaíba (UFV-CRP), Rodovia MG-230, Km 7, Zona Rural, 38810-000, Rio Paranaíba, MG, Brasil. E-mail: martha.almeida@ufv.br

2 Escola Superior de Agricultura "Luiz de Queiroz", Universidade de São Paulo (ESALQ - USP), Piracicaba, SP, Brasil.

* Autor para correspondência. 
Palavras-chave: Salvia hispanica; análises microbiológicas; análises físicoquímicas; aceitação sensorial.

\begin{abstract}
The objective of this study was to develop and evaluate the sensory acceptance of yogurt formulations with chia seeds. After preparation of the formulations (A Control, B - yogurt added of $2 \%$ of chia seeds, C - yoghurt added of $3 \%$ of chia seeds), microbiological and physicochemical analyzes were performed. Hedonic scales were used to verify the acceptance and the intention to purchase the elaborated formulations, as well as the Acceptability Index. The data of the acceptance and purchase intention tests were evaluated through Analysis of Variance (ANOVA), and later, Tukey's Test was applied at a 5\% probability. Yogurt formulations were within the standards required by Brazilian Legislation for microbiological and physicochemical analyzes. There was no significant difference $(p>0,05)$ between the 3 yoghurt formulations for the attributes of flavor, texture and overall impression. However, regarding the appearance attribute, the formulation with $3 \%$ chia (C) seeds was less appreciated $(\mathrm{p}<0,05)$ than the control formulation (A). The formulations with chia seeds ( $\mathrm{B}$ and $\mathrm{C}$ ) had a good sensory acceptance by the evaluators, and the flavor attribute was the most prominent. Among formulations with chia seeds, formulation B presented the best Acceptability Index. There was no significant difference $(p>0,05)$ regarding the average of the purchase intention notes for the 3 yogurt formulations. It was concluded that the yogurt formulations with chia seeds were adequate for the microbiological and physicochemical parameters during the storage period, besides obtaining a good sensorial acceptance, presenting itself as a healthier milk alternative for the consumers.
\end{abstract}

Keywords: Salvia hispanica; microbiological analysis; physicochemical analysis; sensory acceptance.

\section{INTRODUÇÃO}

A formação do hábito alimentar é uma ação complexa, que visa agregar benefícios aos alimentos que fazem parte da rotina diária do consumidor. O desenvolvimento de novos produtos lácteos é importante e representa um desafio para a Ciência e a Tecnologia de Alimentos, visto que grande parte da população almeja melhorar sua qualidade de vida em relação à saúde (SOARES et al., 2011).

O iogurte é produzido a partir da fermentação láctea pelos microrganismos Streptococcus salivarius subsp. thermophilus e Lactobacillus delbrueckii subsp. bulgaricus (CRUZ et al., 2015). Após o crescimento do Streptococcus salivarius subsp. thermophilus, o $\mathrm{pH}$ abaixa parcialmente e o Lactobacillus delbrueckii subsp. bulgaricus inicia seu crescimento com o desdobramento parcial da caseína e a liberação de aminoácidos essenciais (valina e a histidina) para o desenvolvimento dos Streptococcus salivarius, que produzem substâncias promotoras da proliferação dos Lactobacillus delbrueckii. Na primeira fase de incubação há um efeito simbiótico, no qual os dois microrganismos apresentam um melhor crescimento (FERREIRA, 2005). 
$\mathrm{O}$ iogurte pode ser enriquecido com nutrientes que aumentam seu valor nutricional como proteínas, vitaminas, minerais e fibras (CRUZ et al., 2015), ou ser elaborado com a cepa probiótica (Lactobacillus casei PRA205) que produz peptídeos anti-hipertensores (valina-prolina-prolina e isoleucina-prolina-prolina) e compostos antioxidantes, demonstrando sua importância como adjuvante de cultura para a produção de iogurte bi-funcional enriquecido com peptídeos bioativos e células viáveis, que trazem benefícios à saúde do hospedeiro (RUTELLA; TAGLIAZUCCHI; SOLIERI, 2016), principalmente no tratamento da obesidade abdominal (SANTIAGO et al., 2016).

A chia (espécie Salvia hispanica L., família Labiatae) é uma semente que tem se destacado pelo seu elevado conteúdo de ácidos graxos poli-insaturados (linoleico e linolênico), proteínas, fibras e compostos antioxidantes (COELHO; SALAS-MELLADO, 2014). Diversos são os benefícios que ela proporciona à saúde na prevenção e tratamento da obesidade, nas alterações gastrointestinais e nas doenças cardiovasculares, além de contribuir para o controle da glicemia (MONROY-TORRES et al., 2008).

Apesar das sementes de chia serem consumidas há muitos anos no México e nos Estados Unidos da América (ESTILAI; HASHEMI, 1990), seu ingresso no cardápio alimentar brasileiro depende de informações sobre a importância da sua utilização como agentes protetores de doenças e fonte de nutrientes (COELHO; SALAS-MELLADO, 2014).

Após o contato das sementes de chia com um líquido, ocorre a formação de um gel transparente e mucilaginoso, composto principalmente de xilose, glicose e ácido glicurônico que forma um polissacarídeo ramificado utilizado em vários produtos, pois melhora a textura e o valor nutricional dos alimentos (SPADA et al., 2014). A muci- lagem da chia é capaz de absorver 27 vezes o seu peso de água, o que irá contribuir com a saciedade humana, pelo aumento de seu volume na região estomacal (MUÑOZ et al., 2012).

$\mathrm{Na}$ indústria de alimentos, o desenvolvimento de novos produtos permite a constante renovação e sustentação da imagem inovadora que as empresas pretendem construir no mercado, sendo esta uma atividade de fundamental importância para sua sobrevivência (CRUZ et al., 2015). Nos últimos anos, ela vem lançando diversos produtos para conquistar o maior número de consumidores, principalmente devido às alterações nas preferências destes, pois a qualidade dos produtos tem se tornado um importante fator de decisão na hora da compra (CAVALCANTE; MORAIS; RODRIGUES, 2009).

A mucilagem da chia apresentou-se como um bom estabilizante no preparo de sorvetes (CAMPOS et al., 2016), e melhorou a composição nutricional de salsichas sem afetar suas propriedades tecnológicas (PINTADO et al., 2016). Mediante a importância dos produtos lácteos e das sementes de chia na alimentação humana, o desenvolvimento de um iogurte com a presença destas sementes poderá garantir a oferta de um produto mais saudável aos consumidores.

Assim, o objetivo deste estudo foi desenvolver formulações de iogurte com sementes de chia e avaliá-las por meio de técnicas de análise sensorial.

\section{MATERIAL E MÉTODOS}

\section{Elaboração do iogurte com sementes de chia}

Fermentou-se o leite integral com a cultura de Streptococcus thermophilus e Lactobacillus delbrueckii (1:1) na temperatura de $45{ }^{\circ} \mathrm{C}$ por aproximadamente 5 horas, sendo resfriado a $10{ }^{\circ} \mathrm{C}$ e adicionado os 
demais ingredientes no momento da quebra da massa, para a obtenção do iogurte batido (FERREIRA, 2005).

Elaborou-se 3 formulações de iogurte: formulação A (Controle), formulação B (iogurte adicionado de $2 \%$ de sementes de chia) e formulação $\mathrm{C}$ (iogurte adicionado de $3 \%$ de sementes de chia). A quantidade de sementes de chia adicionada em cada formulação foi proporcional à quantidade de leite. A composição de cada formulação está apresentada na Tabela 1.

Elaborou-se as formulações de iogurte no Laboratório de Processamento de Alimentos, Universidade Federal de Viçosa, Campus Rio Paranaíba (MG), onde foram armazenadas em geladeira, em garrafas plásticas de iogurte industrial, à temperatura de $7{ }^{\circ} \mathrm{C}$ até o momento da análise sensorial. Após o processamento, realizaram-se as análises microbiológicas e físico-químicas.

\section{Análises microbiológicas}

Para a determinação dos coliformes totais, diluiu-se $25 \mathrm{~mL}$ das amostras de iogurte em $225 \mathrm{~mL}$ de solução salina peptonada $(0,1 \%)$ e homogeneizou-se durante 60 segundos. A partir desta diluição $\left(10^{-1}\right)$ efetuou-se mais 10 diluições em $225 \mathrm{~mL}$ de solução salina peptonada $(0,1 \%)$. Em seguida, inoculou-se $1 \mathrm{~mL}$ da diluição em uma série de 3 tubos contendo caldo Lauril Sulfato
Triptose (LST). Incubou-se os tubos LST a $35^{\circ} \mathrm{C}$ por 24 horas para observação da produção de gás (BRASIL, 2003).

Para a determinação dos fungos filamentosos e leveduras, adicionou-se $25 \mathrm{~mL}$ de cada uma das formulações de iogurte em $225 \mathrm{~mL}$ de solução salina peptonada $(0,1 \%)$, e em seguida efetuou-se mais 10 diluições. Inoculou-se $0,1 \mathrm{~mL}$ das diluições sobre a superfície de ágar PCA (Plate Count Agar) até sua completa absorção. As placas foram mantidas em câmara incubadora (B.O.D) a $25{ }^{\circ} \mathrm{C}$ por 7 dias, no qual selecionou-se aquelas que possuíam entre 15 e 150 colônias para o cálculo dos microrganismos presentes (BRASIL, 2003).

\section{Análises físico-químicas}

Para a determinação da acidez colocouse $10 \mathrm{~mL}$ de cada amostra de iogurte em um erlemeyer de $50 \mathrm{~mL}$. Em seguida adicionou-se $10 \mathrm{~mL}$ de água destilada e misturou-se até sua completa diluição. Adicionou-se 3 gotas de solução de fenolftaleína e realizou-se a titulação com solução de hidróxido de sódio $(0,1 \mathrm{~N})$, utilizando uma bureta de $25 \mathrm{~mL}$ até a obtenção da coloração rósea (ZENEBON; PASCUET, 2004).

Diluiu-se $10 \mathrm{~mL}$ de cada amostra de iogurte em $100 \mathrm{~mL}$ de água destilada, e após agitação determinou-se o pH das formulações (ZENEBON; PASCUET, 2004).

Tabela 1 - Composição das formulações de iogurtes

\begin{tabular}{lccc}
\hline \multicolumn{1}{c}{ Ingrediente } & Formulação A & Formulação B & Formulação C \\
\hline Leite $(\mathrm{L})$ & 2,00 & 2,00 & 2,00 \\
Açúcar $(\mathrm{g})$ & 200,00 & 200,00 & 200,00 \\
Sementes de chia $(\mathrm{g})$ & - & 40,00 & 60,00 \\
Corante (mL) & 1,00 & 1,00 & 1,00 \\
Essência de morango (mL) & 0,40 & 0,40 & 0,40 \\
Cultura lática (\%) & 0,01 & 0,01 & 0,01 \\
\hline
\end{tabular}




\section{Análise sensorial}

Realizou-se a análise sensorial das formulações de iogurte no $2^{\circ}$ dia após sua elaboração, com 50 avaliadores não treinados, graduandos de vários cursos da Universidade Federal de Viçosa, Campus Rio Paranaíba. Cada avaliador assinou o Termo de Consentimento Livre e Esclarecido, elaborado com base na Resolução n 466/12 (BRASIL, 2012). Realizou-se o estudo após a aprovação do Comitê de Ética em Pesquisa (CEP) da Universidade Federal de Viçosa, protocolo $n^{\circ} 506.155$.

Conduziu-se cada avaliador a uma sala onde realizou-se a análise sensorial. Todos os avaliadores receberam 3 amostras de iogurte (1 amostra de cada formulação) com aproximadamente $20 \mathrm{~mL}$, sendo apresentada de forma aleatória, em copos plásticos sobre bandejas codificadas com números de 3 dígitos, acompanhados de um copo com água mineral a temperatura ambiente para higienizar o palato e assegurar a adequada análise sensorial de cada amostra (REIS; MINIM, 2010).

Para o teste de aceitação utilizou-se uma escala hedônica de 1 a 9 pontos, no qual: $1=$ desgostei extremamente; 2 = desgostei muito; 3 = desgostei moderadamente; 4 = desgostei ligeiramente; 5 = indiferente; $6=$ gostei ligeiramente; $7=$ gostei moderadamente; $8=$ gostei muito; 9 = gostei extremamente. Para o teste de intenção de compra adotou-se uma escala hedônica de 1 a 5 pontos, no qual: 1 = certamente compraria; 2 = provavelmente compraria; 3 = tenho dúvidas se compraria; $4=$ provavelmente não compraria; $5=$ certamente não compraria. Ambos os testes foram realizados segundo Moraes (1988).

Calculou-se o Índice de Aceitabilidade (IA) pela equação descrita por Castro et al. (2007), onde:

$\mathrm{IA}=$ (Nota média obtida pelo produto/

Nota máxima atribuída ao produto) x 100

\section{Avaliação da vida útil das formulações}

Para a avaliação da vida útil das formulações de iogurte determinou-se o pH e a acidez nos dias $0,7,14$ e 28 . As análises microbiológicas foram realizadas no tempo zero (dia zero logo após sua elaboração) e no último dia de estocagem (dia 28) (SIVIERE; OLIVEIRA, 2002).

\section{Análise estatística}

Avaliaram-se os dados de aceitação e das notas da intenção de compra pela Análise de Variância (ANOVA), com um post roc de Tukey, a 5\% de probabilidade, no programa Statistical Package for the Social Sciences (SPSS), versão 20.0.

\section{RESULTADOS E DISCUSSÃO}

Após a fermentação (dia zero) e aos 28 dias de armazenamento, observou-se que todas as formulações cumpriram os requisitos exigidos pela Legislação Brasileira (BRASIL, 2007) para coliformes a $35^{\circ} \mathrm{C}$, não sendo realizadas as análises microbiológicas a $45^{\circ} \mathrm{C}$, devido à ausência de produção de gás nos tubos. Não houve o crescimento de fungos e leveduras em ambos os tempos analisados.

Após 5 horas de fermentação, as formulações de iogurtes (A, B e C) apresentaram os valores de $\mathrm{pH}$ de 4,67; 4,62 e 4,59; respectivamente. Tais resultados foram similares àquele obtido por Macchione (2007) em leite fermentado, no qual obteve-se um pH de 4,6. Segundo Silva (2007), quando a fermentação prossegue até o $\mathrm{pH}$ de 4,6 a estabilidade do produto potencializa-se, destacando que as formulações de iogurtes elaboradas neste estudo já estavam estabilizadas conforme este parâmetro.

No final do processo de fermentação dos iogurtes, a formulação A apresentou $0,74 \%$ de ácido lático e as formulações B e C 
apresentaram $0,75 \%$, sendo que Pereira (2002) identificou $0,73 \%$ de acidez para sua formulação de iogurte.

Os microrganismos do iogurte inicialmente convertem parte da lactose em ácido lático, ocasionando uma diminuição do $\mathrm{pH}$ até um ponto que a caseína se torna insolúvel e a viscosidade do leite aumenta. Gradualmente, a produção de ácido lático começa por desestabilizar os complexos de caseína e as proteínas do soro desnaturadas, solubilizando o fosfato de cálcio e os citratos. As micelas de caseína vão se associando e coalescem parcialmente a medida que se aproxima do ponto isoelétrico, que varia de 4,6 a 4,7 (TAMINE; ROBINSON, 1991).

No final do período de estocagem, os valores de $\mathrm{pH}$ das formulações $\mathrm{A}, \mathrm{B}$ e C foram de 3,99; 3,92; e 3,81 (Figura 1). $\mathrm{O}$ iogurte por estar sujeito a alterações em seus componentes, deve ser acompanhado de análises periódicas de $\mathrm{pH}$ e acidez para determinar o grau de segurança para o consumo humano.

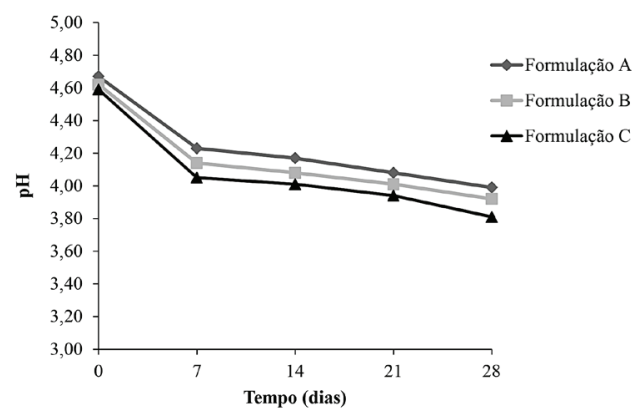

Figura 1 - Valores de $\mathrm{pH}$ durante o período de estocagem das formulações de iogurte. Formulação A - controle; Formulação B - 2\% de sementes de chia; Formulação B - 3\% de sementes de chia

Martin (2002) identificou valores de $\mathrm{pH}$ entre 4,0 e 4,4 em iogurte comercial armazenado durante 30 dias, e Pereira (2002) obteve para um iogurte tradicional, um $\mathrm{pH}$ no $1^{\circ}$ e $28^{\circ}$ dia de 4,50 e 4,05 , respectivamente. Zerbielli (2014) identificou no $14^{\circ}$ dia de estocagem um pH de 4,1 no iogurte com 3\% de sementes de chia.

Os valores de acidez aumentaram durante os 28 dias de estocagem (Figura 2), sendo que todas as formulações de iogurte estavam dentro dos padrões exigidos pela Legislação Brasileira quanto à acidez, que deve variar de 0,6 a 1,5\% de ácido lático no final do tempo de estocagem (BRASIL, 2007).

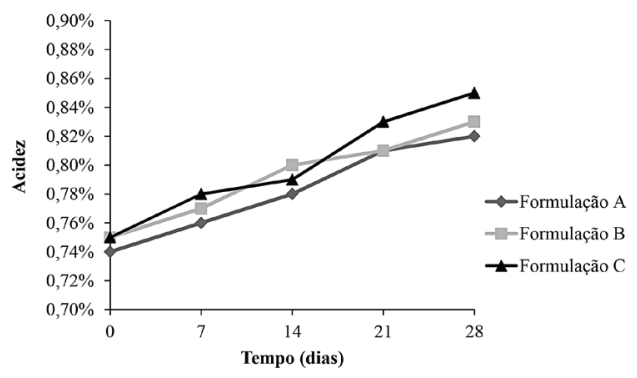

Figura 2 - Valores de acidez (\% de ácido lático) durante os 28 dias de estocagem das formulações de iogurtes. Formulação A controle; Formulação B - 2\% de sementes de chia; Formulação C - 3\% de sementes de chia

Durante o armazenamento de iogurtes, Pereira (2002) identificou os valores de $0,73 \%$ de acidez no $1^{\circ}$ dia de armazenamento e $0,94 \%$ no $28^{\circ}$ dia, enquanto Martin (2002) obteve de 0,73 a $1,17 \%$.

Observou-se neste estudo que $62 \%$ $(\mathrm{n}=31)$ dos avaliadores eram do gênero masculino, 72\% tinham até 20 anos completos e possuíam uma renda mensal familiar de 1 a 5 salários mínimos. Quanto à frequência de ingestão de iogurtes, $16 \%(\mathrm{n}=8)$ dos avaliadores relataram consumir este alimento diariamente; $30 \%(\mathrm{n}=15)$ de 3 a 4 vezes por semana; $46 \%(n=23)$ de 1 a 2 vezes por semana; $6 \%(n=3)$ uma vez a cada quinzena, e $2 \%(n=1)$ uma vez ao mês.

Não houve diferença significativa $(\mathrm{p}>0,05)$ entre as 3 formulações de iogurte 
em relação aos atributos sabor, textura e impressão global (Tabela 2). Entretanto, quanto ao atributo aparência a formulação A (controle) foi mais apreciada $(\mathrm{p}<0,05)$ que a formulação C ( $3 \%$ de sementes de chia), não havendo diferença significativa $(\mathrm{p}>0,05)$ entre as formulações com sementes de chia para nenhum dos atributos avaliados. As diferentes formulações apresentaram boa aceitação, uma vez que todos os atributos avaliados (sabor, textura, aparência e impressão global) tiveram notas hedônicas médias superiores a 6 pontos, equivalente ao termo "gostei ligeiramente".

Cunha et al. (2009) destacam que as características sensoriais como sabor, textura e aparência estão entre os principais determinantes na aquisição, consumo, aceitação e preferência dos produtos alimentícios por diferentes faixas etárias, além de contribuírem para o monitoramento de sua qualidade.

No atributo sabor obteve-se o melhor escore de notas entre as formulações com sementes de chia ( $\mathrm{B}$ e $\mathrm{C}$ ), apresentando a pontuação média de 7,16 e 7,28 que equivale a "gostei moderadamente", sugerindo que o sabor foi a característica que mais agradou aos avaliadores. Tais resultados foram semelhantes aos de Silva (2007), com os iogurtes probiótico e prebiótico nas diferentes con- centrações de microrganismos $(0,5 \% ; 1,0 \%$ e $1,5 \%$ ), o qual obteve notas médias, no atributo sabor, que variaram de 6,9 (gostei ligeiramente) a 7,4 (gostei moderadamente)

Não houve diferença significativa $(\mathrm{p}>$ $0,05)$ entre as formulações de iogurte quanto o atributo textura. As pontuações variaram entre 6,10 e 6,44, equivalendo a "gostei ligeiramente", independente da adição de sementes de chia, sugerindo uma aceitação entre os avaliadores. Pereira et al. (2012) obtiveram notas médias variando de 6,60 a 7,80 para este atributo, equivalendo aos termos hedônicos "gostei ligeiramente" e "gostei moderadamente".

Houve diferença significativa $(\mathrm{p}<0,05)$ quanto à aparência entre as formulações $\mathrm{A} e$ $\mathrm{C}$, sugerindo que a presença das sementes de chia na sua forma intacta possa ter influenciado neste atributo, sendo destacado por Bezerra (2010), que a aparência exerce a maior influência na hora da compra do produto pelo consumidor.

$\mathrm{Na}$ impressão global, as formulações de iogurte apresentaram escores médios entre 6,80 e 7,00; situando-se entre os termos "gostei ligeiramente" e "gostei moderadamente", caracterizando uma aceitação do produto, sendo que Cavalcante, Morais e Rodrigues

Tabela 2 - Valores de média e desvio padrão das notas hedônicas do teste de aceitação, e Índice de Aceitabilidade para as formulações de iogurtes, mediante os atributos avaliados

\begin{tabular}{c|c|c|c|c|c|c}
\hline \multirow{2}{*}{ Atributo } & \multicolumn{3}{|c|}{ Teste de Aceitação } & \multicolumn{3}{c}{ Índice de Aceitabilidade (\%) } \\
\cline { 2 - 7 } & $\begin{array}{c}\text { Formulação } \\
\text { A }\end{array}$ & $\begin{array}{c}\text { Formulação } \\
\text { B }\end{array}$ & $\begin{array}{c}\text { Formulação } \\
\text { C }\end{array}$ & $\begin{array}{c}\text { Formulação } \\
\text { A }\end{array}$ & $\begin{array}{c}\text { Formulação } \\
\text { B }\end{array}$ & $\begin{array}{c}\text { Formulação } \\
\text { C }\end{array}$ \\
\hline Sabor & $6,82 \pm 1,13^{\mathrm{a}}$ & $7,16 \pm 1,07^{\mathrm{a}}$ & $7,28 \pm 1,17^{\mathrm{a}}$ & 75,78 & 79,56 & 80,89 \\
\hline Textura & $6,10 \pm 1,45^{\mathrm{a}}$ & $6,44 \pm 1,44^{\mathrm{a}}$ & $6,24 \pm 1,49^{\mathrm{a}}$ & 67,78 & 71,56 & 69,33 \\
\hline Aparência & $6,96 \pm 1,67^{\mathrm{a}}$ & $6,44 \pm 1,46^{\mathrm{ab}}$ & $6,14 \pm 1,78^{\mathrm{b}}$ & 77,33 & 71,56 & 68,22 \\
\hline $\begin{array}{c}\text { Impressão } \\
\text { global }\end{array}$ & $6,80 \pm 1,22^{\mathrm{a}}$ & $7,00 \pm 1,02^{\mathrm{a}}$ & $6,92 \pm 1,32^{\mathrm{a}}$ & 75,56 & 77,78 & 76,89 \\
\hline
\end{tabular}

Formulações de iogurte com letras iguais na linha não diferiram estatisticamente entre si pelo Teste de Tukey a $5 \%$ de probabilidade. Ausência de letras demonstra que não teve diferença estatística. 
(2009), obtiveram notas médias de 7,08; 6,43 e 5,28 em iogurtes adicionados de amêndoas da castanha de caju. Zerbielli (2014) ao avaliar uma bebida láctea observou, na análise da impressão global, que suas formulações com $1 \% ; 3 \%$ e $5 \%$ de sementes de chia apresentaram notas médias de 8,21 a 8,33 ; entre os termos "gostei moderadamente" e "gostei extremamente".

Segundo Castro et al. (2007), um produto é considerado aceito, em termos sensoriais, quando apresenta um Índice de Aceitabilidade maior que $70 \%$. A partir da avaliação deste Índice de Aceitabilidade, observou-se que entre os iogurtes com sementes de chia, a formulação B foi mais aceita que a formulação $\mathrm{C}$, uma vez que ela apresentou nota superior a 70\% em todos os itens avaliados (Tabela 2).

Com relação à análise da intenção de compra, as formulações de iogurte com sementes de chia (B e C) obtiveram o maior percentual de respostas na nota $2(54 \%$ e $38 \%$, respectivamente), que corresponde ao termo "provavelmente compraria" (Figura 3). Este resultado indica que a avaliação foi positiva, pois tais formulações atingiram os maiores percentuais na intenção de compra, assim como Oliveira e Damin (2003) para as formulações de iogurte com 12,5 e $25,0 \%$ de polpa de araticum.

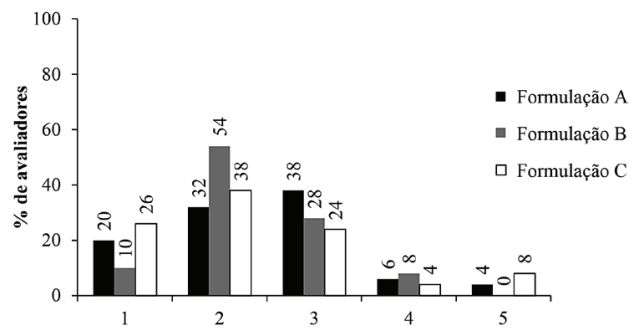

Figura 3 - Frequência relativa dos avaliadores, segundo a nota atribuída na intenção de compra das formulações de iogurte. Formulação A - controle; Formulação B - 2\% de sementes de chia; Formulação C - 3\% de sementes de chia
Não houve diferença significativa ( $\mathrm{p}>$ $0,05)$ quanto à média geral das notas na intenção de compra para as formulações de iogurte que foram de 2,42 $\pm 1,00$ (formulação A); 2,34 $\pm 0,76$ (formulação B) e 2,30 $\pm 1,14$ (formulação C).

\section{CONCLUSÕES}

As formulações de iogurte com sementes de chia mantiveram-se dentro dos padrões da Legislação Brasileira para as análises microbiológicas e físico-químicas, e foram bem aceitas pelos avaliadores, quando comparadas com a formulação controle (A), e o atributo sabor foi o que apresentou a maior nota média.

A maioria dos avaliados atribuiu nota equivalente a "provavelmente compraria" para o iogurte com $2 \%$ de sementes de chia (formulação B), e tal formulação obteve Índice de Aceitabilidade superior a 70\% em todos os itens avaliados, sendo, portanto, sugerida como a melhor formulação para futuras reproduções industriais.

Assim, o iogurte com sementes de chia é uma alternativa saudável para os consumidores, uma vez que tais sementes são fontes de ácidos graxos essenciais e fibras.

\section{REFERÊNCIAS}

\section{BEZERRA, M. F. Caracterização físico- química, reológica e sensorial de iogurte obtido pela mistura dos leites bubalino e caprino. 2010. 116 f. Dissertação (Mestrado em Engenharia Química) - Universidade Federal do Rio Grande do Norte, Natal, 2010.}

BRASIL. Ministério da Agricultura, Pecuária e Abastecimento. Instrução Normativa $\mathrm{n}^{\circ} 46$ de 23 de outubro de 2007. Regulamento Técnico de Identidade e Qualidade de Leites Fermentados. Diário Oficial da União, 24 de outubro de 2007. s. 1, p. 5. 
BRASIL. Ministério da Agricultura, Pecuária e Abastecimento. Instrução Normativa $n^{0} 62$ de 26 de agosto de 2003. Métodos Analíticos Oficiais para Análises Microbiológicas para Controle de Produtos de Origem Animal e Água. Diário Oficial da União, 18 de setembro de 2003, s. 1, p. 14.

BRASIL. Ministério da Saúde. Resolução

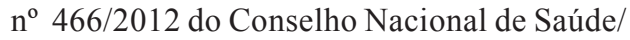
MS. Diretrizes e Normas Regulamentadoras de Pesquisa envolvendo Seres Humanos. Diário Oficial da União, 12 de dezembro de 2012.

CAMPOS, B. E. et al. Optimization of the mucilage extraction process from chia seeds and application in ice cream as a stabilizer and emulsifier. Food Science and Technology, v. 65 , p. 874-883, 2016.

CASTRO, L. I. A. et al. Quinoa (Chenopodium quinoa Willd): digestibilidade in vitro, desenvolvimento e análise sensorial de preparações destinadas a pacientes celíacos. Alimentos e Nutrição, v. 18, n. 4, p. 413-419, 2007.

CAVAlCANTE, J. M.; MORAIS, A. C. S.; RODRIGUES, M. C. P. Efeito da adição de amêndoas da castanha de caju nas propriedades sensoriais do iogurte adoçado com mel. Revista Brasileira de Tecnologia Agroindustrial, v. 3, n. 1, p. 1-14, 2009.

COELHO, M. S.; SALAS-MELLADO, M. L. M. Revisão: composição química, propriedades funcionais e aplicações tecnológicas da semente de chia (Salvia hispanica L.) em alimentos. Brazilian Journal of Food Technology, v. 17, n. 4, p. 259-268, 2014.

CRUZ, R. G. et al. Desenvolvimento e avaliação sensorial de iogurte adicionado de "caviar" de cenoura por crianças. Revista do Instituto de Laticínios Cândido Tostes, v. 70, n. 3, p. 132-140, 2015.
CUNHA, C. S. et al. Influência da textura e do sabor na aceitação de cremes de aveia por indivíduos de diferentes faixas etárias. Alimentos e Nutrição, v. 20, n. 4, p. 573580, 2009.

ESTILAI, A.; HASHEMI, A. Chromosome number and meiotic behavior of cultivated chia, Salvia hispanica (Lamiaceae). Hort Science, v. 25, n. 12, p. 1646-1647, 1990.

FERREIRA, C. L. L. F. Produtos lácteos fermentados (aspectos bioquímicos e tecnológicos). $3^{\mathrm{a}}$ ed. Viçosa: Editora UFV, 2005.

MACCHIONE, M. M. Qualidade e estabilidade de "leite fermentado tratado termicamente": propriedades físicoquímicas, microbiologia e aceitação sensorial. 2007. 65 f. Dissertação (Mestrado em Tecnologia de Alimentos) - Universidade Estadual de Campinas, São Paulo, 2007.

MARTIN, A. F. Armazenamento do iogurte comercial e o efeito na proporção das bactérias láticas. 2002. 62 f. Dissertação (Mestrado em Ciências) - Universidade de São Paulo, São Paulo, 2002.

MONROY-TORRES, R. et al. Protein digestibility of chia seed (Salvia hispanica L). Revista Salud Publica y Nutrición, v. 9, n. 1, p. 12-21, 2008.

MORAES, M. A. C. Métodos para a avaliação sensorial dos alimentos. $7^{\mathrm{a}} \mathrm{ed}$. Campinas: Unicamp, 1988.

MUÑOZ, L. A. et al. Chia seeds: microstructure, mucilage extraction and hydration. Journal of Food Engineering, v. 108, n. 1, p. 216-224, 2012.

OLIVEIRA, M. N.; DAMIN, M. R. Efeito do teor de sólidos e da concentração de 
sacarose na acidificação, firmeza e viabilidade de bactérias do iogurte e probióticas em leite fermentado. Ciência e Tecnologia de Alimentos, v. 23, p. 172-176, 2003.

PEREIRA, G. G. et al. Influência do $\mathrm{pH}$ nas características físico-químicas e sensoriais de frozen yogurt de morango. Semina: Ciências Agrárias, v. 33, n. 2, p. 675-686, 2012.

PEREIRA, M. A. G. Efeito do teor de lactose e do tipo de cultura na acidificação e pós-acidificação de iogurtes. 2002. 105 f. Dissertação (Mestrado em Tecnologia de Alimentos) - Universidade Estadual de Campinas, São Paulo, 2002.

PINTADO, T. et al. Strategies for incorporation of chia (Salvia hispanica L.) in frankfurters as a health-promoting ingredient. Meat Science, v. 114, p. 75-84, 2016.

REIS, R. C.; MINIM, V. P. R. Teste de aceitação. In: MINIM, V. P. R. Análise sensorial: estudos com consumidores. $2^{\mathrm{a}} \mathrm{ed}$. Viçosa: Editora UFV, 2010. Cap. 3, p. 66-82.

RUTELLA, G. S.; TAGLIAZUCCHI, D.; SOLIERI, L. Survival and bioactivities of selected probiotic lactobacilli in yogurt fermentation and cold storage: new insights for developing a bi-functional dairy food. Food Microbiology, v. 60, p. 54-61, 2016.

SANTIAGO, S. et al. Yogurt consumption and abdominal obesity reversion in the PREDIMED study. Nutrition, Metabolismand Cardiovascular Diseases, v. 26, n. 6, p. 468-475, 2016.
SILVA, S. V. Desenvolvimento de iogurte probiótico com prebiótico. 2007. $107 \mathrm{f}$. Dissertação (Mestrado em Ciência e Tecnologia dos Alimentos) - Universidade Federal de Santa Maria, Santa Maria, 2007.

SIVIERI, K.; OLIVEIRA, M. N. Avaliação da vida-de-prateleira de bebidas lácteas preparadas com "fat replacers" (Litesse e Dairy-lo). Ciência e Tecnologia de Alimentos, v. 22, n. 1, p. 24-31, 2002.

SOARES, D. S. et al. Aproveitamento de soro de queijo para produção de iogurte probiótico. Arquivos Brasileiros de Medicina Veterinária e Zootecologia, v. 63, n. 4, p. 996-1002, 2011.

SPADA, J. C. et al. Caracterização física, química e sensorial de sobremesas à base de soja, elaboradas com mucilagem de chia. Ciência Rural, v. 44, n. 2, p. 374-379, 2014.

TAMINE, A. Y.; ROBINSON, R. K. Yogurt: ciência y tecnologia. Zaragoza: Acribia, 1991.

ZENEBON, O.; PASCUET, N. S. Métodos físico-químicos para análise de alimentos. $4^{\mathrm{a}}$ ed. São Paulo: Câmara Brasileira do Livro, 2004.

ZERBIELLI, K. M. Bebida láctea fermentada com cultura probiótica adicionada de semente de chia (Salvia hispânica L.). 2014. 66 f. Dissertação (Mestrado em Tecnologia de Alimentos) - Universidade Tecnológica Federal do Paraná, Londrina, 2014. 